\title{
Gramática, Uso e Norma: \\ a Contribuição de Maria Helena de Moura Neves ao Ensino ${ }^{1}$
}

Marli Quadros Leite*

\section{Introdução}

Neste trabalho homenageio Maria Helena de Moura Neves e ressalto a importância de suas pesquisas no campo do ensino, especialmente no que diz respeito aos conceitos de uso, norma e gramática. Pretendo mostrar como a autora deixa claro que a exata compreensão desses conceitos, por parte dos professores, é de fundamental relevância para uma prática de ensino eficaz da língua materna. Além disso, viso a enfatizar como Maria Helena interpreta, avalia e critica o trabalho escolar com "a gramática", sem nunca, todavia, deixar de assumir postura construtiva diante dessa questão. Para tanto, analisar-se-ão, principalmente, as obras A gramática na escola (1990), A gramática - história, teoria e prática (2002) e Que gramática estudar na escola? Norma e uso na língua portuguesa (2003).

Divido, então, este texto em duas partes: na primeira, trato da exploração inicial da autora quanto ao trabalho dos professores com a gramática, isto é, do diagnóstico do ensino de gramática, das interpretações, da avaliação e das sugestões formuladas com base na pesquisa empreendida em NEVES (1990). Na segunda, exploro o desdobramento desse trabalho, que se constrói, mais enfaticamente, sobre o conceito e norma. Para evitarem-se mal-entendidos, é preciso afirmar, de partida, que o fio condutor do trabalho de Maria Helena sempre foi o uso, o que quer dizer que seu discurso e prática fizeram-se a partir da consideração e observação empírica da língua em funcionamento, da modalidade falada ou escrita, sempre apoiados na teoria funcionalista.

\section{Ponto de partida: a gramática na escola}

Para falar do problema do ensino de gramática portuguesa na escola, Maria Helena empreendeu uma pesquisa, no final dos anos 80 do século XX, em que colheu opiniões e avaliou posições de 170 professores, do ensino fundamental e médio, a

\footnotetext{
${ }^{1}$ Uma versão, oral, deste artigo foi apresentada em uma mesa-redonda no Congresso de Linguística em Homenagem a Maria Helena de Moura Neves, realizado na UNESP / Araraquara, nos dias 06 a 08 de agosto de 2008.

(USP/CNPq)
} 
respeito de suas concepções teóricas e de suas práticas de ensino da gramática no âmbito do que se compreende como "aula de português", ou de ensino de língua materna. Essa pesquisa, que deu origem ao livro Gramática na escola; renovação do ensino da gramática; formalismo x funcionalismo; análise da gramática escolar, publicado pela editora Contexto, em 1990, na coleção Repensando a Língua Portuguesa, constituiu a base empírica para a reflexão da autora sobre o assunto e, por isso, foi recorrentemente retomada nos trabalhos posteriores, muitos dos quais reunidos nas duas obras (de 2002 e 2003) de que nos servimos aqui para construir nossos comentários.

As pesquisas posteriores à de 1990 desenvolvem o que a autora construiu e mostrou em Gramática na escola, que tem dois capítulos: no primeiro, "Situação do ensino de gramática na escola", há a descrição do "estado de arte" sobre o problema enfocado. Essa análise tem duas perspectivas: $1^{\mathrm{a}}$. a da análise de como o objeto gramática é trabalhado pelos professores (o quê, para quê e como ensinar gramática) e com base em que tipo de bibliografia (manuais ou livros didáticos); $2^{\mathrm{a}}$. a da análise da formação dos professores, do contexto social em que estão inseridos e de seus objetivos quanto ao ensino de gramática; no segundo capítulo, "A gramática escolar", a autora oferece uma proposta de ensino da gramática, que deve ter com base o texto, dentro de uma perspectiva funcionalista da língua, ou seja, da língua real em uso, como se passará a comentar a seguir.

Meu objetivo não é o de repetir o texto e Maria Helena, mas o de chamar a atenção para as posições que tomou frente ao problema analisado. A principal constatação a que a autora chegou foi relativa ao despreparo do professor para o ensino da língua, pois esse é o problema gerador dos demais: do ensino taxionômico, da incapacidade de reconhecer e analisar as entidades sintáticas em seus diferentes contextos, da impossibilidade ou incapacidade de eleger teorias próprias ao ensino da língua, da repetição de livros didáticos e de manuais de gramática, da incapacidade de formular objetivos pertinentes ao ensino da língua etc.

O despreparo do professor, como destaca a autora, só seria e será eliminado pela atuação eficaz dos cursos universitários de Letras, que pudessem e possam formar professores capazes de fazer o aluno refletir sobre a língua e de ensinar como ela funciona. Para e a partir disso, a terminologia e as regras fariam sentido e deixariam de ser irreais e estáticas. Esse problema, contudo, parece ser de difícil solução, pois, embora os professores que participaram da pesquisa tivessem curso superior, nenhum sabia conduzir adequadamente o ensino da língua, e todos agiam como se jamais tivessem analisado a língua a partir de outra perspectiva que não a tradicional. Assim se pronuncia Maria Helena sobre esse ponto:

Quanto a essa preocupação normativa, cabe observar aqui que, embora $100 \%$ dos professores pesquisados tenham formação universitária plena, e embora a finalidade principal apontada para o ensino da gramática não seja a normatividade, como aqui se apontou, a pergunta sobre a 'teoria' subjacente ao ensino da gramática empreendido teve como resposta quase geral 'gramática tradicional'. (1990, p. 43) 
Como a pesquisa apontou, muitos (ou alguns) professores se ressentiam, por uma série de fatores, da impossibilidade de realizar trabalho mais eficiente, embora não se mobilizassem para solucionar os problemas com os quais se defrontavam. No máximo, procuravam participar de cursos de capacitação (naquela época, denominados cursos de reciclagem, atualização ou aperfeiçoamento) oferecidos pela Secretaria de Educação. O que nos interessa destacar sobre esse ponto é a observação de Maria Helena sobre a ineficácia desses cursos rápidos (em geral de 30 horas) ministrados por professores das universidades, os quais pregavam a substituição do ensino normativo por outro fundamentado em teorias linguísticas modernas (estruturalista, gerativista etc.). Com estas palavras a autora fala desse problema:

Essa [a substituição do ensino de gramática normativa pelo de gramática descritiva] é a resposta dos professores à cobrança de uma 'modernização do ensino da gramática, já que a ênfase no ensino de normas de uso da língua ficou suficientemente estigmatizado para que o professor negue a manter-se nele (ou se negue a confessar que nele se mantém).

Como o tempo disponível para os cursos de "reciclagem" nunca foi suficiente para que se maturasse uma proposta, seu resultado, isto é, a repercussão desses cursos nas aulas de português, sempre foi a substituição de terminologias, da tradicional pela estruturalista, por exemplo, o que dava apenas um verniz de modernidade às aulas de português, mas que não mudava a essência do ensino. Ao contrário, estabelecia-se um conflito entre a escola, de um lado, a família e a sociedade de outro, que cobravam o ensino das regras do "bom uso" da língua. A opinião, acertada e atual, da autora é a de que somente a educação continuada é solução para o problema da má formação dos mestres.

Um ponto fundamental da pesquisa de Maria Helena é o da comprovação de os professores não trabalharem com base em concepção clara e correta de gramática. Para eles, como foi constatado, a gramática é apenas o conjunto das regras que podem levar o aluno a um melhor desempenho linguístico, especialmente no que diz respeito à modalidade escrita. Como aponta a autora, nenhum dos pesquisados mostrou preocupação com a análise e interpretação do funcionamento da língua, e a análise das respostas revelou que o ensino se baseava (e se baseia, ainda hoje, quando há o ensino de gramática) em definições de classes de palavras e de entidades sintáticas.

Com base, então, em um diagnóstico seguro, que revelou um quadro desolador da situação do ensino da língua portuguesa em São Paulo - que foi aqui apenas aqui esboçado -, Maria Helena refletiu e construiu sólida proposta, fundamentada nos princípios teóricos do funcionalismo. Assim, ela recomendou e recomenda que a análise deve partir da realidade da língua, e não da língua irreal e estática, representada por exemplos forjados, ou frases descontextualizadas, pinçadas da literatura. Para a autora, isso é imprescindível, pois pensa que

(...) é a língua em funcionamento que tem de ser objeto de análise em nível pedagógico, já que a compartimentação da gramática como disciplina desvinculada do uso da língua tem sido um dos grandes óbices à própria legitimação da gramática como disciplina com lugar no ensino da língua portuguesa. 
A proposta esboçada por Maria Helena tem como alicerce o texto, que é "a unidade básica na análise da língua em funcionamento", com fundamento, nessa fase, especialmente nas obras de Halliday (1967/68, 1973, 1985). Posteriormente, como mostrarei adiante, essa base amplia-se.

Em poucas páginas, Maria Helena constrói um programa, ainda hoje atualíssimo - mesmo vinte anos depois - e que pode ser adotado em cursos de formação de professores de língua portuguesa, em nível de graduação, em cursos de pós-graduação lato sensu, ou em cursos de capacitação de profissionais em serviço. Esse projeto de ensino, como tal proposição pode ser considerada, apresenta-se de modo simples, embora guarde sua complexidade.

A leitura desatenta desse projeto pode escamotear um fato importante: o de o texto ser uma unidade que engloba o discurso e todos os níveis de análise linguística (sintático, semântico, morfológico e fonológico) que devem ser considerados no todo, mas distintamente operacionalizados. O manejo em separado, por exemplo dos níveis sintático e semântico, permite, como demonstra Maria Helena, que o aluno distinga, dentre outros, fenômenos gramaticais de semânticos, como sujeito de tema.

Depois de verificados os principais problemas relativos ao ensino de português, Maria Helena parte para a concretização de sua proposta de ensino de gramática fundamentado na observação do funcionamento da língua em uso, tomando como unidade de análise o texto.

Assim, com base em três postulados, Maria Helena monta um programa a partir do qual é possível trabalhar a leitura e a produção de textos integrados à gramática: o texto como organização da informação, como organização da interação e como organização semântica. O fundamento da proposta é, em resumo, o seguinte:

1. O texto como organização da informação.

1.1 A organização informativa no texto:

a. o desempenho linguístico.

b. a compreensão de peculiaridades do sistema da língua na organização dos blocos informativos.

1.2 A organização informativa na oração.

2. O texto como organização da interação.

2.1 As modalidades de frase.

$2.2 \mathrm{O}$ modo verbal.

2.3 As pessoas do discurso.

3. A organização semântica do texto.

3.1 A transitividade.

3.2 A coesão textual:

a. quanto à esfera das relações e processos.

b. quanto à esfera dos participantes/argumentos.

Como se pode perceber claramente, estão contemplados, pelo texto, os níveis linguístico (o sistema), pragmático (a interação) e discursivo (as modalidades, as pessoas do discurso). Esse programa, então, desenvolvido com o suporte teórico funcionalista, possibilitaria que o ensino cumprisse sua finalidade de, conforme manifestação dos professores, apoiados nos documentos elaborados oficialmente para 
sistematizar o ensino de língua portuguesa no Brasil, "levar o aluno a se expressar melhor".

Finalmente, é imprescindível observar que a proposta inverte o procedimento de trabalho com o ensino da língua: em vez de o professor partir do estudo da forma e das definições para alcançar e explicar o funcionamento da língua, estratégia que sempre se mostrou ineficaz, deve partir do funcionamento da língua ${ }^{2}$. Ressalte-se, todavia, que, segundo essa proposta, no nível do ensino fundamental e médio, o aluno manipula as formas da língua desvinculadamente de classificações e definições. Em nível, superior, porém, o estudo metalinguístico torna-se imprescindível para que o graduando possa, ao tornar-se profissional, ser capaz de ensinar a gramática com base em uma teoria linguística determinada, como, por exemplo, a funcionalista.

\section{A proposta amadurecida: assunção de posições}

Muitos dos trabalhos posteriores o de 1990, sobre a questão do ensino de gramática, foram reunidos em 2002 (A gramática: história, teoria e análise, ensino) e 2003 (Que gramática ensinar na escola? Norma e uso na Língua Portuguesa). Nesses textos, a autora refina e amplia sua proposta, sem desviar-se, contudo, da rota já estabelecida. A leitura atenta desses trabalhos é fundamental para que perceba com mais nitidez a ideia lançada.

Em que consiste, então, o refinamento da proposta? Primeiro, na ampliação da bibliografia, extremamente visível no trabalho de 2002; depois, no aprofundamento teórico-prático dos pontos apresentados, por meio de novas reflexões, comentários e análise de exemplos. Essas novas reflexões incluíram de modo enfático, especialmente no texto de 2003, a discussão sobre a norma linguística ${ }^{3}$.

Quanto à bibliografia que dá sustentação à reflexão de Maria Helena acerca do ensino da gramática, antes assentada eminentemente nos trabalhos de Michael Halliday, incluiu textos de outros autores, dentre os quais os mais citados são Talmy Givón (1979, 1984, 1995), Simon Dik (1978, 1980, 1989, 1997), Du Bois (1993), Coseriu (1958, 1992 [1988]). Além desses, outros textos da própria autora (Neves 1987, 1997, 2000), publicados depois de 1990, apóiam e reforçam o desenvolvimento da matéria.

A questão da norma linguística, como problema teórico discutido de modo sistematizado, não aparece senão na obra de 2003, que é resultado de pesquisas publicadas em periódicos científicos. Pelas datas de publicação de artigos que tratam do tema, conclui-se que esse foi um assunto sobre o qual Maria Helena se debruçou especialmente no período de 2001 a 2003, ano em que deu à luz também o Guia de usos do português: confrontando regras e usos.

\footnotetext{
${ }^{2}$ Cf. NEVES (2010).

${ }^{3}$ Ver também novas reflexões sobre ensino e norma linguística em NEVES (2010).
} 


\subsection{Os aportes à proposta}

Segundo Maria Helena, uma das constatações mais "graves", feitas com base na pesquisa de 1990, foi a de que "ensinar gramática não serve para nada", tal como foi afirmado por vários professores. Isso porque, conforme analisou e explicou a pesquisadora, os mestres, embora "ensinassem gramática", não sabiam o que fazer nesse domínio e, portanto, não viam resultado de seu trabalho, tendo em vista que os alunos não apresentavam melhoras no desempenho linguístico, objetivo buscado pela escola.

O ensino de gramática na escola, como Maria Helena se certificou, resumia-se no exercício da metalinguagem, com preocupação normativa, fundamentada em valores (bonito e feio) e julgamentos sociais (certo e errado). Essa prática mostrou-se ineficaz, por não levar o aluno a melhor desempenho linguístico. Incentivados pelos discursos ouvidos em cursos de aperfeiçoamento, onde ressoavam teorias linguísticas modernas, e apoiados nos livros didáticos que, naturalmente, vão incorporando essas teorias, 0 professor abandonou a prática normativa, adotou novas teorias, mas continuou a prática do estudo meramente metalinguístico, resumido na explanação de definições e paradigmas, .

O texto, objeto que entrou na aula de português para, em tese, solucionar o problema do ensino descontextualizado e baseado na exploração pura e simples de paradigmas, definições e normas de bom uso, não foi bem tratado. Não foi tomado como uma unidade de sentido formada por uma conjunção de fatores, linguísticos e extralinguísticos, que constroem seu tecido, foi encarado como um pretexto, um fornecedor de palavras e frases que, como antes, seriam analisadas isoladamente de sua malha. Essa verificação levou Maria Helena a retomar sua proposta e, cada vez mais, explicitá-la, explicá-la e ampliá-la.

Em 1990, como já mostrei antes, o programa de ensino já havia sido esboçado completamente sobre o texto, a partir das expressões "organização informativa, organização da interação e organização semântica", com base na teoria de Halliday (1967-68, 1973, 1985). Na obra de 2002 a mesma teoria alicerça a análise, apenas com terminologia um pouco diferente, pois, nesse caso, Maria Helena usa explicitamente a denominação das funções da linguagem, segundo Halliday, para re-explicar o que dissera e, também, oferecer exemplos de análise calcados na teoria apregoada. Desse modo, segundo penso, vai construindo um modelo de análise que, se não for possível ser aproveitado diretamente pelos professores de ensino fundamental e médio, poderá, ou deverá, sê-lo pelos ministrantes de cursos de graduação, especialização ou capacitação, que, com certeza, terão clara ideia da realidade do ensino de língua portuguesa nas escolas, pela leitura desses textos de Maria Helena.

O quadro a seguir apresentado resume a sugestão da autora, centrada na análise do texto que, conforme suas palavras, "codifica o discurso" e "é a unidade maior de investigação da língua em função, exatamente a unidade na qual se manifesta o complexo das funções que a língua exerce por meio da combinação das unidades 
menores." (2002, p. 241). Essas funções, relacionadas aos fenômenos que lhe são concernentes, aparecem no quadro seguinte:

\begin{tabular}{|l|l|}
\hline \multicolumn{1}{|c|}{ Função } & \multicolumn{1}{|c|}{\begin{tabular}{c}
\multicolumn{1}{c|}{ Fenômeno } \\
(discursivo-textual-gramatical)
\end{tabular}} \\
\hline Ideacional & $\begin{array}{l}\text { Transitividade (predicadores nominais e } \\
\text { verbais) }\end{array}$ \\
\hline Interpessal & $\begin{array}{l}\text { Sujeito } \\
\text { Modalidades } \\
\text { Modalizações }\end{array}$ \\
\hline Textual (discursivo) & $\begin{array}{l}\text { Fóricos (demonstrativos, possessivos, artigos } \\
\text { definidos) } \\
\text { Coordenadores }\end{array}$ \\
\hline
\end{tabular}

\subsection{Assunção de posições}

É absolutamente relevante destacar algumas posições de Maria Helena frente ao problema que analisou. Em todos os seus escritos sobre a questão do ensino de gramática (assim como sobre outros assuntos) suas opiniões são precisas, justas. A verdade desta minha afirmação pode ser comprovada pela leitura de uma entrevista que concedeu à esta revista Linha D'Água, da Associação de Professores de Língua e Literatura (APLL), em 1996, e que, depois, foi reelaborada e incorporada ao livro de 2002, como um capítulo, intitulado "Questões ligadas ao ensino de gramática". Nesse texto, as opiniões da autora, sobre alguns temas às vezes polêmicos, às vezes tabus, são explicitadas cristalinamente, como passarei a mostrar, seguindo os subtítulos pelos quais se distribui a matéria.

1. O ensino a gramática no ensino fundamental e médio: a abordagem gramatical mais adequada para se enfrentarem as questões decorrentes do fato de que há uma interface texto-gramática. 
A escola precisa definir o objetivo do ensino da gramática e, nesse bojo tem de estar incluído o melhor desempenho linguístico (passivo, ativo, oral e escrito) do aluno. A gramática a ser trabalhada deve ser funcional, isto é, aquela que, segundo explica

trata a língua na situação de produção, no contexto comunicativo. Basta lembrar que saber expressar-se numa língua não é simplesmente dominar o modo de estruturação de suas frases, mas é saber combinar essas unidades sintáticas em peças comunicativas eficientes, o que envolve a capacidade de adequar enunciados às situações, aos objetivos da comunicação e às condições de interlocução. E tudo isso se integra na gramática. (2002, p. 226)

\section{A perspectiva do fato gramatical no ensino a gramática: gramática do português falado ou gramática do português escrito.}

A escola deve entender que as modalidades linguísticas, tanto a falada quanto a escrita, não são opostas entre si, mas complementares, e ambas se assentam sobre "um mesmo mecanismo gramatical que sustenta o processo e que garante o uso.". A compreensão disso, diz ainda a autora, "pode auxiliar a adequação dos textos de uma e de outra modalidade.” (2002, p.227-8)

\section{A importância da vertente tradicional dos estudos gramaticais e a contribuição das teorias mais recentes.}

A partir de uma atitude imparcial, a autora comenta as duas posições - uma positiva e outra negativa - existentes entre, de um lado, pesquisadores e, de outro, professores de português sobre a gramática tradicional, a fim de mostrar como nenhuma das duas posições se sustenta sobre argumentos sólidos. Os que têm atitude positiva diante da gramática tradicional são apenas 'condescendentes', e os que a têm negativa reagem a ela a partir de argumentos vazios ou óbvios. Mesmo a cientificidade reivindicada para os estudos linguísticos, em oposição à gramática tradicional, hoje perdeu o sentido, já que a 'ciência linguística' está voltada para temas como competência comunicativa e diacronia.

Para fechar esse ponto, Maria Helena diz que normatividade era ainda tabu, ninguém ousara defendê-la. Mas, numa atitude intelectualmente buliçosa, faz uma provocação, talvez por já reconhecer que "língua e norma" ou "gramática e norma" são conceitos que, como ela disse sobre a relação texto e gramática, "não se estranham", ao contrário, são interdependentes. A desconfiança dessa relação aparece no seguinte parágrafo de Maria Helena (2002, p. 29):

Normatividade ninguém ainda ousa defender. Mas deve lembrar-se que, se gramática não tem a ver com norma, por ouro lado o desempenho eficiente, em certos registros, depende da 
confrontação do texto a determinados padrões vigentes e aceitos na sociedade. Será essa a próxima tônica? (grifei)

A resposta a essa pergunta de Maria Helena talvez já seja sim, tamanho é o interesse que muitos especialistas têm demonstrado sobre a questão da normatividade na e da língua. Dentre esses destaco Sylvain Auroux (1998) que tem, na França, e de lá para o mundo, defendido a tese da normatividade da língua e, também, da linguística ${ }^{4}$.

\section{As relações entre a pesquisa acadêmica e ensino fundamental e médio.}

Sobre esse ponto a atitude de Maria Helena é crítica, especialmente em relação à atuação a universidade em sua relação com o ensino fundamental e médio. A primeira crítica diz respeito à incompetência da academia para resolver os problemas que detecta sobre o fracasso do ensino de português, ao não conseguir se organizar para promover ações contínuas e efetivas no sentido de solucionar os problemas que chega a levantar. Como os contatos dos professores universitários com os do ensino médio são episódicos, isso desencadeia outro problema, segundo denuncia a autora, que é o da opressão e da intimidação que o discurso da academia exerce sobre o professor. A segunda refere-se também à opressão, só que em sentido inverso, pois o professor universitário é oprimido por exigências institucionais que o obrigam a fazer docência, pesquisa e extensão - sem que se saiba bem qual é a natureza dessa última - o que leva o docente universitário às episódicas participações e interferências no ensino fundamental e médio. As palavras corajosas de Maria Helena sobre isso são as seguintes:

Essa falta de compromisso implica - insisto -, levar para os professores de ensino fundamental e médio 'interessantes' resultados da última pesquisa que tivermos feito, pois, com certeza, se ela foi interessante pra nós, há de ser para eles. E quanto mais hermética ela for, mais respeito teremos, e mais estaremos gratificados com o respeito que tivermos obtido, ao final de nossa interação. Pensando bem, o que não terá havido - não está havendo - é diálogo!

\section{A questão do registro a ser trabalhado na escola: a defesa da norma culta padrão e o respeito ao registro (popular) do aluno.}

Esse título resume a atitude de Maria Helena diante da questão do tratamento do dialeto e do registro do aluno: a linguagem do aluno deve ser respeitada, mas a escola tem o dever de torná-lo proficiente também em outros dialetos e registros. Assim a autora se pronuncia:

é papel da escola prover para seus alunos a formação necessária para que eles sejam usuários da língua no padrão necessário à ocupação de posições minimamente situadas na escala social”, e,

\footnotetext{
${ }^{4}$ Veja-se, sobre esse tema, a posição de LEITE (2007).
} 
mais adiante continua "também se espera da escola que ela não crie um cotejo entre registros que constitua estigmatização e banimento para o alado do aluno. (2002, p. 231)

\section{A questão da atualização do professor do ensino médio.}

Esse ponto está relacionado com o número 4, e a posição de Maria Helena, como já destaquei, é a de que deve haver uma continuidade de ações (da universidade ou de outras instâncias) voltadas à capacitação do professor. $\mathrm{O}$ tom da crítica, contudo, em relação à ação da academia dirigida ao ensino médio, se completa. Aqui, ela afirma, ainda mais claramente, que a simples transposição de conhecimentos da academia para o ensino médio é inócua e que os professores universitários não estão preparados para essa tarefa de promover a atualização dos professores do ensino básico. Leia-se o texto:

(...) acredito que as ações sobre professores de ensino fundamental e médio não podem resumir-se a uma transposição do conhecimento acumulado em pesquisas de nível universitário. Despejar esses conteúdos - mesmo facilitados - sem prover a sua integração na ação pedagógica é simplesmente sacudir a poeira e jogá-la sobre alguém. Mesmo pesquisas consideradas mais práticas, pesquisas rotuladas como de Linguística aplicada não constituem 'conteúdo que deva ser levado para as salas de aula de cursos de atualização de professores de ensino básico. Na verdade, pelo que me é dado conhecer, alvo exceções, os professores universitários não estão preparados para atuar eficientemente nessa função: eles também têm de ser preparados para isso. E tem de haver um plano muito bem pensado, orgânico, continuado, maior do que cada um dos governos que se sucedem.

\section{O papel do livro didático no ensino de gramática.}

A opinião de Maria Helena sobre o livro didático é a de que hoje os livros estão melhores que os de algum tempo atrás, mas a relação do professor com ele ainda é difícil. A razão da dificuldade decorre da dimensão e do papel que o mestre quer atribuir ao livro: em vez de simples auxiliar do ensino, ele o transforma em bibliografia principal para suas consultas e, ainda, espera que o livro cumpra sozinho a sua tarefa, a de ensinar.

8. O trabalho com o aluno como leitor, e o apelo fácil da televisão, do videocassete e dos videogames $e$ o uso do CD-ROM com fins pedagógicos e a disputa de espaço com o professor.

Sobre esses dois pontos, a visão de Maria Helena não é desfavorável: ao contrário, ela entende que os recursos da eletrônica e informática oferecem novas 
possibilidades de conhecimento para os alunos e que cabe à escola saber explorá-los a fim de torná-los, também, ferramentas complementares de aprendizagem.

Depois da exposição desse ponto, em resumo, o que fica de contribuição efetiva, da parte de Maria Helena, para o ensino? Sem medo de errar, digo que ficam duas contribuições preciosas: uma, é um resultado parecido com uma ultrassonografia do ensino de gramática, acompanhada de um relatório minucioso e competente, que transforma uma discussão que até então era dispersa e vaga em uma discussão produtiva sobre um fato concreto. Só para mostrar a verdade dessa afirmação, observem-se os seguintes pontos que, pela voz da própria Maria Helena, sumariam a questão, numa espécie de relatório do exame realizado:

- O professor de ensino médio tem necessidade de conhecimentos de linguística para bem equacionar o tratamento que dará ao ensino da gramática; esse conhecimento abrange a compreensão de que não se transferirão meramente, aos alunos lições de linguística aprendidas nas universidades.

- Nenhum tratamento dado à gramática pode perder de vista o sistema. Não se trata, porém de se oferecer aos alunos o sistema, arrumado em esquemas e paradigmas; um contato desse tipo alcança, no máximo, que os alunos atuem como repetidores. Só pela reflexão sobre a língua se chega clarividentemente ao sistema que a regula.

- A reflexão sobre a língua, no nível médio, só pode partir do uso diretamente observável, da observação da língua em função, com a compreensão de que existe um amálgama de componentes, desde o pragmático até o fonológico. Afinal, se, como dizem os professores, a finalidade do ensino é o bom uso da língua, parece evidente que se deva refletir sobre a língua em uso. E, (...) embora as palavras sejam unidades evidentes a qualquer observador da língua, seu valor só se determina com a configuração de fazer o texto. (2002, p. 263)

A outra contribuição é a proposta concreta, já mostrada aqui, a partir da qual os interessados (governos, universidades) podem elaborar seus planos de ataque ao problema da má qualidade do ensino brasileiro, não sem antes atentarem para as críticas às tentativas ocasionais e descomprometidas que mais atrapalham que ajudam a resolver o problema do ensino de português no Brasil.

\section{Novo ponto de partida: a norma linguística na escola.}

Na obra de 2003, Que gramática estudar na escola?, antes referida, Maria Helena se volta à discussão detida a questão da norma linguística a fím de, assim, fornecer subsídios para que os professores, e os interessados em geral, possam entender a relação língua / norma e gramática / norma.

$\mathrm{Na}$ Apresentação, a autora declara a natureza da obra e a situa no âmbito do conjunto de suas reflexões sobre o tratamento escolar a linguagem. Nesse momento, é imprescindível transcrever o que Maria Helena afirma no primeiro parágrafo do livro: 
O conjunto de pesquisa aqui apresentado liga-se à preocupação de que se institua um tratamento escolar mais científico das atividades de linguagem, muito especificamente das atividades ligadas à gramática de língua materna. Assenta-se a necessidade de uma gramática escolar que não apenas contemple uma taxonomia e um elenco de funções mas que, legitimada pela sua relação com o uso efetivo da língua, dê conta dos usos correntes atuais, não perdendo de vista o natural e eficiente convívio de variantes no uso linguístico, incluída, aí, a norma tradicionalmente considerada padrão.

Essa declaração não deixa dúvidas acerca da posição da autora sobre o papel da escola diante do impasse de "ensinar ou não ensinar" a norma padrão/culta na escola, criado por alguns defensores da suposta "liberdade normativa". Logo de partida, como se vê, defende que a escola deve ocupar-se da língua em uso e, portanto, de todas as normas, inclusive aquela tida como a de maior prestígio sociocultural, a denominada norma padrão. Maria Helena avança para a exposição do problema, procurando apresentá-lo a partir de várias perspectivas, tecendo, pois, reflexão pertinente e esclarecedora sobre todos os pontos que se propõe discutir. Tomaremos aqui os pontos mais importantes dessa discussão para mostrar a sabedoria da autora também quanto ao tratamento dessa questão.

Para tanto, a autora dividiu o livro em três partes: na primeira, faz uma análise da situação do tratamento da norma na escola, apresenta as bases teóricas nas quais se apóia para operar os conceitos de língua, norma e padrão, em torno dos quais gira o ensino de gramática; na segunda, faz uma discussão teórica pormenorizada sobre os conceitos de gramática, uso e norma; na terceira, relaciona mais de perto os conceitos de norma, uso e gramática escolar, porque abre muito mais a lente na direção da escola, tendo em vista que, de um lado, discute pontualmente assuntos que constituem problemas para os professores de português e, de outro, oferece sua proposta para o ensino, ao tempo em que a explica por meio de análises concretas de textos falados e escritos de diferentes gêneros, que incluem diálogos espontâneos, entrevistas, quadrinhos, charges, trechos de romances e poesias dentre outros.

A discussão que Maria Helena tece sobre gramática e norma funda-se, além de em suas próprias reflexões e teorias, desenvolvidas nas obras 1987, 1997, 2000, em teorias desenvolvidas por Eugenio Coseriu, especialmente nas obras de 1951 e 1988, e por Carlos Faraco (2002) no que concerne mais diretamente à denominação da norma como padrão. Dentre diversos outros autores, a autora cita alguns antigos (por exemplo, Aristóteles, Retórica; Dante, De vulgari eloquentia) e modernos - alguns estrangeiros (Labov; Halliday, Stevens e McIntosh; Claire Blanche-Benveniste) e outros tantos brasileiros (Rosa Virgínia Mattos e Silva; Roberto Camacho).

Como as posições de Maria Helena são firmes e precisas, sua contribuição, também nesse domínio, é facilmente perceptível, o que pode favorecer a resolução de uma série de dúvidas que os professores costumam ter sobre a relação gramática e norma e sobre o papel da escola diante de questões que envolvem a variação linguística e o ensino, ou a consideração, ou não, do ensino da norma padrão (da norma culta).

Para "limpar o terreno" e discutir o problema com propriedade, Maria Helena desfaz um erro comum concernente à natureza da gramática tradicional, tida "simplistamente" como normativa, mas que se constituiu muito mais complexamente, pois em seu berço, na Grécia antiga, serviu antes como uma arte, uma técnica, que 
visava a sistematizar as regras da língua, pela observação e descrição dos textos literários, aqueles considerados os que melhor representassem a língua, dentre os quais, especialmente, os de Homero. Dessa descrição da língua em paradigmas, revelava-se o grego modelar, que devia ser imitado, em oposição aos falares dele divergentes, considerados bárbaros. Historicamente, pois, ela explica, a gramática não se construiu sobre a égide apenas da normatividade do "dever-ser", mas também do "ser". Nesse contexto, a gramática teve um fim prático, o de preservar uma língua e literatura que estavam sob ameaça.

Não obstante a ausência de razões que justifiquem sua tendência normativa e padronizadora, como aquelas da antiguidade que cercaram a língua grega, a gramática seguiu esse curso, mesmo depois dos avanços da ciência linguística no campo da Sociolinguística. Por que isso? pergunta-se Maria Helena, para responder:

\begin{abstract}
Os verdadeiros gramáticos sabem tudo isso, e obviamente pautam suas lições pelo que sabem. Entretanto, se há uma área do conhecimento em que as descobertas da Linguística têm caído no vazio é a área da disciplina gramatical, seja a considerada pela escola, seja a considerada pelo usuário da língua. Estamos longe de ver o cidadão comum e o professor reconhecendo que a variação linguística é nada mais que a manifestação evidente da essência e da natureza da linguagem, reconhecendo que há um padrão valorizado, sim, mas que o uso do padrão prestigiado não constitui, em si, e intrinsecamente, um uso de boa linguagem, e que essa avaliação só ocorre pelo viés sociocultural, condicionado pelo viés socioeconômico.
\end{abstract}

Esse trecho mostra a clareza do pensamento de Maria Helena sobre, de um lado, o estatuto dos diversos registros versus o do registro padrão e, de outro, a natureza desse último que se constitui pela importância social, política e cultural a ele atribuído. A escola, diz a autora inúmeras vezes no livro, não deve desconsiderar nenhum registro, nem os vários que a ela chegam na boca e na ponta dos dedos dos alunos - para lembrar que hoje eles "teclam" e escrevem - nem outros que não dominam muitas normas, dentre os quais ao padrão ou culta, que o aluno, que não teve oportunidade de conhecer no seio da família ou de seu círculo social mais próximo, deve aprender a dominar na escola.

A escolha do padrão a ser ensinado, contudo, é, conforme adverte a autora, ainda, problema no Brasil. Isso se deve ao fato de haver muitos outros gêneros, além dos literários, hoje considerados importantes à sociedade - como os jornalísticos, por exemplo - que, portanto, podem ser, como aqueles, tomados como padrão para a língua em funcionamento, no que concerne ao registro culto escrito. Para a modalidade falada, inúmeras pesquisas, como as produzidas no âmbito do grupo da Gramática do Português Falado $^{6}$ e do Projeto NURC $^{7}$, a respeito da norma linguística praticada nos cinco estados envolvidos, têm sido desenvolvidas. Todo esse trabalho, porém, ainda ressente de sistematização para ser mais acessível ao grande público e, especialmente, vale dizer, ao professores de ensino básico e aos alunos de graduação.

Nesse campo, também, a sugestão de Maria Helena é a que a escola passe a conduzir o ensino no sentido inverso do que tem feito, assim como recomendou sobre o

\footnotetext{
5 Sobre uma reflexão sobre norma linguística, consulte-se, também, Auroux (1998), Mattos e Silva (2002), Faraco (2002), Barros (2006) e Leite (2007).

${ }^{6}$ Cf. Castilho (1990).

${ }^{7}$ Cf. Preti (1987) e Bentes; Leite (2010).
} 
ensino da gramática, quando indicou que é do texto que se chega à gramática e não o contrário. Assim, ela aconselha que para levar o aluno a alcançar o padrão, a escola deve partir da língua em uso em direção ao padrão, e não o inverso, isto é, dos paradigmas do próprio padrão para observação disso em textos, ou somente em trechos, literários tomados isoladamente como se fossem a língua e dela representassem o padrão.

Dentre tantas ideias relevantes de Maria Helena sobre a questão da norma a linguística, quero ressaltar nesse momento uma delas, por ser a que atinge sua essência, isto é, o caráter intrínseco da norma relativamente à língua. Digo isso por entender que, se a língua é uma atividade humana, se resulta do comportamento social e se é percebida pelo que se chama aqui de "usos", que podem ser considerados mais ou menos adequados a cada situação comunicativa, não se pode negar o seu caráter normativo. As palavras afirmativas de Maria Helena sobre "a validade do conceito de norma” são as seguintes (2002, p. 50):

\footnotetext{
Ora, é a própria consideração da funcionalidade da língua que leva à consideração de que a noção de norma (e não apenas no sentido que lhe dá Coseriu (1967 [1951]) mas também no sentido de 'modelo') é inerente à noção de uso linguístico. A primeira ressalva, entretanto, que é ligada também à consideração da funcionalidade da língua -, naturalmente dos usos linguísticos, exatamente por isso a elas não pode vincular-se nenhuma noção de autoridade (auctoritas): é do próprio uso (usus) que emergem os padrões de adequação que compete observar e seguir, se o que se busca é o bom desempenho em termos socioculturais. São padrões que 'gramáticos' poderão registrar examinando-lhes a natureza e as condições de uso, mas que nenhum gramático poderá instituir como modelo ditando-os com sua autoridade.

Nem linguisticamente nem socioculturalmente fica aberto o terreno para que indivíduos (por mais especialistas que sejam) pontifiquem sobre qual seja a norma legítima.
}

Esse trecho resume a questão: a consideração da língua, e não apenas de parte dela, engloba todos os seus usos, ou melhor, todas as suas normas, porque, afinal, uso e norma não são conceitos que, usando mais uma vez a expressão de Maria Helena, se estranham, ao contrário, são conceitos que se complementam, se se entender que a norma é a contraparte social do uso, e que esse apenas epilinguisticamente pode ser considerado individual, mas que como tudo o que é linguístico é social, é também ele resultado social, embora com recortes e nuanças individuais e, portanto, é normativo.

\section{Conclusão}

Da leitura da obra de Maria Helena sobressaem certezas, mesmo quando o assunto é tão difícil de ser equacionado como o é tudo o que diz respeito ao ensino da gramática e sua complexa rede. As certezas sobre as quais falamos são:

- O ensino da língua em uso.

- A abordagem do texto como unidade de análise que leva à gramática. 
- A consideração e tratamento da variação linguística.

- A consideração e ensino da variante padrão.

- A assunção da inerência da norma à língua.

A contribuição de Maria Helena ao ensino de língua portuguesa é precis, é exposto com precisão e ressai, precisamente, de pontos como os que vão aqui citados:

I. Reconhecimento de que somente pelo aproveitamento dos conhecimentos produzidos pela ciência linguística é possível equacionar os problemas do ensino de língua no Brasil.

II. Afirmação de que os cursos de Letras têm o papel fundamental para conduzir à solução o problema da formação adequada de professores, pela preparação de pessoal competente para operar teorias linguísticas convenientes à análise e ensino da língua em função.

III. Advertência de que somente ações efetivas e continuadas terão alguma importância e ressonância na capacitação de docentes em serviço.

IV. Indicação de que é papel da escola tratar a língua em uso, considerando sua heterogeneidade.

V. Formulação de proposta concreta para o ensino da língua em funcionamento, com base no texto, sua unidade de análise.

VI. Oferecimento de modelos de análise que ilustram a proposta formulada, sobre pontos fulcrais da constituição do enunciado, tratando, de um lado, questões discursivotextuais, como a referenciação, e de outro, questões gramaticais (ou escolhas gramaticais) resultantes de processos interacionais, como predicação e transitividade, organização temática da oração etc.

VII. Esclarecimentos fundamentais sobre a natureza da gramática e da disciplina gramatical e de temas concernidos, assim como da natureza do uso e da norma linguística.

VIII. Elucidação de dúvidas acerca de dicotomias (ou falsas dicotomias) relacionadas ao ensino da língua, tais como: certo x errado; uso x norma-padrão; língua falada x língua escrita; descrição x prescrição.

Outros pontos igualmente relevantes e importantes são tratados nas obras aqui examinadas, aqui, entretanto, foram escolhidos alguns, por entender-se que, de modo global são os que tangenciam aqueles que ficaram silenciados. Ressalto, como é óbvio, que nada é mais esclarecedor que a leitura da obra de Maria Helena e a ela remeto todos os interessados nas questões aqui comentadas sumariamente. 


\section{Referências bibliográficas}

Fontes primárias:

NEVES, Maria Helena de Moura (1990). Gramática na escola; renovação do ensino da gramática; formalismo x funcionalismo; análise da gramática escolar. São Paulo : Contexto. Col. Repensando a Língua Portuguesa.

UNESP. . (2002). A gramática - história, teoria e análise, ensino. São Paulo : Editora - (2003). Que gramática estudar na escola? Norma e uso na língua portuguesa. São Paulo : Contexto.

Fontes secundárias:

NEVES, Maria Helena de Moura. (1987). A vertente grega da gramática tradicional. São Paulo : HUCITEC.

. (2000). Gramática de usos do português. São Paulo : Ed. UNESP.

. (2001). Língua falada, língua escrita e ensino: reflexões em torno do tema.

In: URBANO, H. et alii (orgs.). Dino Preti e seus temas: oralidade, literatura, mídia ensino. São Paulo : Cortez.

Ed. UNESP.

. (2003). Guia de uso do português. Confrontando regras e usos. São Paulo :

. (2010). Ensino de língua e vivência de linguagem. Temas em confronto.. São Paulo: Editora Contexto, 2010.

Estudos:

AUROUX, Sylvain. (1998a). La raison, le langage et les normes. Paris : PUF.

BARROS, Diana Luz Pessoa de. (2000). Conceitos e imagens da norma no português falado no Brasil: o discurso da gramática. Texto inédito.

BARROS, Diana Luz Pessoa de. (2006) . O discurso da gramática: imagens da norma e da língua. Lingüistica (Madrid), v. 17, p. 95-113, 2006. 
CAMACHO, Roberto. (1985). O sistema escolar e o ensino da língua portuguesa. Alfa. São Paulo, v. 29, p. 1-7.

CASTILHO, A. T. de (1990). O português culto falado no Brasil (história do Projeto NURC/BR) In: PRETI, D.; URBANO, H. (org.) (1990). A linguagem falada culta na cidade de São Paulo: estudos. São Paulo: TA Queiroz; Fapesp. Vol. 4.

COSERIU, E. (1958). Sincronia, diacronia y historia. Montevidéu : Universidad.

.(1967) Teoria del lenguage y lingüística general. Madrid : Gredos.[1951]

. (1992). Competencia lingüística. Elementos de la teoría del hablar. Tradução espanhola. Madrid : Gredos. [1988]

. (1979). Sincronia, diacronia e história - o problema da mudança lingüística. Trad. do espanhol por Carlos Alberto da Fonseca e Mário Ferreira. Rio de Janeiro : Presença/EDUSP. [1 ${ }^{\mathrm{a}}$ ed. 1973, Editorial Gredos]

. (1980). Lições de lingüística geral. Trad. do italiano por Evanildo Bechara. Rio de Janeiro : Ao Livro Técnico.[1973]

. (1987). Teoria da linguagem e lingüística geral - cinco estudos. Trad. do espanhol por Agostinho Dias Carneiro. Rio de Janeiro : Presença. [1 ${ }^{\text {a }}$ ed. 1961, Gredos]

FARACO, Carlos (2002). Norma-padrão brasileira. In: Bagno, M. (org.). Linguística da norma. São Paulo : Edições Loyola, p. 37-61.

GIVÓN, Talmy. (1979). Syntax and semantics: discourse and syntax. v. 12. New York: Academic Press, . (1984). Syntax. New York : Academica Press.

$\overline{\text { Benjamins. }}$

(1995). Functionalism and grammar. Amsterdan / Philadelphia : John

HALLIDAY, M. A. K. (1973). The functional basis of language. In: Bernstein, B. (ed.). Class, codes, and control. Londres : Routledge and Kegan Paul.

. (1985). An introduction to functional grammar. Baltimore : Edward Arnold.

HALliDAY, M. A. K.; McINTOSH; STEVENS, P; McINTOSH, A. (1974). As ciências lingüísticas $e$ o ensino de línguas. Trad. do inglês de Miriam Lemle et al. Petrópolis : Vozes

LABOV, W. (1972). Sociolinguistics patterns. Philadelphia : University of Pennsylvania.

. (1994). Principles of linguistic change. Oxford / Cambridge : Blackwell.

LEITE, Marli Quadros. (2007). O nascimento da gramática portuguesa: uso e norma. São Paulo : Humanitas / Paulistana. 
MATTOS E SILVA, Rosa Virgínia. (1989). Tradição gramatical e gramática tradicional. São Paulo : Contexto. Col. Repensando a Língua Portuguesa.

(2002). Variação, mudança e norma (movimentos no interior do português brasileiro). In: Bagno, M. (org.). Linguística da norma. São Paulo : Edições Loyola, p. 291-316.

PRETI, D. (org.) (1987). A linguagem falada culta na cidade de São Paulo: materiais para seu estudo. São Paulo: T. A. Queiroz; Fapesp Vol. 2.

\begin{abstract}
In this paper, linguist Maria Helena de Moura Neves is honored; the importance of her researches in the teaching field are highlighted, especially those studies referring to the concepts of use, norms and grammar. We aim at showing how the author makes it clear that the precise understanding of these concepts by teachers is essential for an effective teaching of the mother tongue. Besides, we aim to emphasize how Maria Helena interprets, evaluates and criticizes the school work carried out in the "grammar" field, without ever abandoning her positive constructive attitude in this matter. To meet the stated objectives, three pieces of work will be analyzed: A gramática na escola (1990) - Grammar at school -, A gramática - história, teoria e prática (2002) - Grammar - history, theory and practice-, and Que gramática estudar na escola? Norma e uso na língua portuguesa (2003) - Which Grammar to study? Norms and usage in Portuguese. The text is divided in two sessions: in the first, the author's initial investigations on the works of teachers with grammar will be looked into, i.e., grammar teaching diagnostics, as well as interpretations, assessments, suggestions. This analysis is based on the researcher's work of 1990. In the second session, the means by which the mentioned research unfolds is explored - bearing in mind that it is more emphatically constructed in terms of the concept of norm. The underlying factor that permeates Maria Helena's works has always been language usage, which is to say that her discourse and her practice have been built on reflection and empirical observation of language in use, both in its speaking and writing modes, and always supported on the functional theory.
\end{abstract}

Key-Words: Teaching; grammar; linguistic norm; linguistic usage. 